\title{
Reagan assailed by laser weapon lobbies
}

Hawks say go:

\section{doves argue}

\section{caution}

\section{Washington}

An early confrontation seems to be brewing between the Administration of incoming president $\mathrm{Mr}$ Ronald Reagan and members of the scientific community concerned with international arms control over plans to develop laser weapons for use in space.

Key congressional Republicans are said to have been told by members of $\mathrm{Mr}$ Reagan's transition team for the Defense Department that he wants to increase research and development on the use of lasers to destroy incoming ballistic missiles. One report claims that an early launch of the National Aeronautics and Space Administration's space shuttle will test an aiming device for a space-based laser, a project code-named Talon Gold.

But these rumoured plans are coming under strong attack from scientists who claim that laser weapons systems would not only be extremely costly and of dubious technical value, but that an accelerated research programme could upset the chances of negotiating an agreement over how such weapons should be controlled.

Speaking at last week's meeting of the American Association for the Advancement of Science (AAAS) in Toronto, for example, Dr Richard Garwin, chief scientist at IBM's Thomas Watson Research Center, claimed that excessive emphasis on directed-energy space weapons diverts funds and talent from more serious and more effective threats.

Mr Reagan's quoted views are compatible with a report from the science and technology subcommittee of the Senate Commerce Committee, which says that if rumours of an impending commitment by the Soviet Union to develop laser weapons are to be taken seriously, then there should be a significant increase in support for the Defense Department's research programme in the area.

The Senate committee admits that there is an "unsettling" diversity of opinion within the US scientific community about the technical and economic feasibility of high-energy lasers in a wide variety of potential applications, including defence, but it points out that the present Department of Defense budget allocations for high-energy laser research are not sufficient to achieve operational weapons as early as would otherwise seem possible. An increase in funds and commitment by the department would, it says, "significantly accelerate the achievement of directed energy weapons systems", a view apparently shared by leading members of Mr Reagan's defence transition team.

The Senate report provides some insight into the controversy about US efforts in laser weapons research that has simmered within the Pentagon for several years. The controversy surfaced in 1979 with reports in Aviation Week that the Soviet Union had begun to build a large high-energy laser at Sary-Shagan, a weapons testing area near the Chinese border, and that this appeared to be the first step towards a fullblown laser weapons system able to destroy both satellites and incoming missiles.

Defence officials have been divided on how to respond. Some - in particular, Dr William Perry, Under-Secretary of Defense for Research and Technology have played down the potential threat, arguing that the gap between theory and practice was so large that the Soviet Union was unlikely to have a weapons system in operation until the $1990 \mathrm{~s}$, and rejecting claims that the Soviet Union had a significant strategic advantage in this area.

Others in the Pentagon have been dissatisfied with this reaction, and have been pushing for an aggressive laser weapons research programme, demanding substantial increases over the current $\$ 215$ million a year being devoted to the highenergy laser research, primarily in the Air Force and by the Defense Advanced Projects Agency.

The dominant thinking within the Carter Administration has been that the main emphasis should remain on research. The report of the Senate committee apparently now in agreement with $\mathrm{Mr}$

Reagan's advisers - is that research alone is not enough, and that " a balance between technology development and weapons system development"' is nceded.

The committee suggests, for example, that a special of fice be created within the Department of Defense to manage and direct the overall high-energy laser programme of the department, rather than distributing its research and development efforts across the different services. And it endorsed a bill introduced by Senator Howell Heflin of Alabama to create a National Laser Institute to coordinate all laser research and development.

Fears that such enthusiasm may be allowed to flourish relatively unbridled. under the new administration are prompting the members of the arms control community to argue strongly that the national security implications of even an accelerated research programme should be carefully considered.

In a recent report from the department of physics at the Massachusetts Institute of Technology, Kosta Tsipis and Michael Callaham point out that, over and above the severe technical and economic hurdles facing the development of a full laser weapons system, even a research programme could be upsetting to strategic arms limitation talks, since it would be difficult to tell whether the research was for defensive or offensive purposes.

In his paper to AAAS, Dr Garwin argued in a similar vein that space-based lasers would be highly vulnerable to attack by anti-satellite rocket vehicles, which could be developed with a fraction of the resources required to install the space weapons.

David Dickson

\section{European science portfolios still for grabs}

\section{Brussels}

The division of portfolios among the new members of the European Commission last week has left scientific research in the dark. The next few days should give the cabinets of the principal commissioners, Etienne Davignon and Ivor Richard, the new British commissioner, a chance to sort out their division of responsibilities.

So far it seems that Davignon, a Belgian viscount, will be taking over responsibility for all energy and industrially related matters, while Ivor Richard will take over the rest of research, science and education. This will involve some reshuffling of the bureaucracy, but nobody is prepared to predict what effect these changes at the top will have on policy.

Davignon, now entering his second four year stint as commissioner in charge of industrial affairs, has become one of the most powerful figures in Brussels through his handling of the steel crisis. He takes over responsibility for energy from the now departed German, Guido Brunner, and has already made it clear that he aims at a tough energy-orientated policy to revive European industry.

His chief interest in research is likely to be the development of energy-efficient technology, alternative energy sources and research aligned with industrial innovation. A notable advocate of Community programmes in telematics (the marriage of chip technology and telecommunications) and bioengineering, it is doubtful whether, with the broadening of his responsibilities, he will have much time to devote to the poorer aspects of Community research programmes.

This leaves Ivor Richard in charge of the joint research centres, education and training, which will tie in neatly with his responsibility for employment and social affairs. Another new commissioner, KarlHeinz Narjes from the right-wing German CDU party, has been given undefined portfolios for industrial innovation, nuclear safety and environment and consumer pro- 